\title{
Response of Ecosystem Carbon and Water Vapor Exchanges in Evolving Nocturnal Low-Level Jets
}

\author{
Jinkyu Hong*, Nathalie Mathieu ${ }^{1)}$, Ian B. Strachan ${ }^{1)}$, Elizabeth Pattey ${ }^{2)}$ and Monique Y. Leclerc ${ }^{3)}$ \\ Department of Atmospheric Sciences/Global Environment Lab, Yonsei University, Korea \\ ${ }^{1)}$ Department of Natural Resource Sciences, McGill University, Canada \\ ${ }^{2)}$ Eastern Cereal and Oilseed Research Center, Agricultural and Agro-Food Canada, Canada \\ ${ }^{3)}$ Lab for Environmental Physics, University of Georgia, USA
}

*Corresponding author. Tel: +82-2-2123-5693, E-mail: jhong@yonsei.kr

\begin{abstract}
The nocturnal low-level jet makes a significant impact on carbon and water exchanges and turbulent mixing processes in the atmospheric boundary layer. This study reports a case study of nocturnal surface fluxes such as $\mathrm{CO}_{2}$ and water vapor in the surface layer observed at a flat and homogeneous site in the presence of low-level jets (LLJs). In particular, it documents the temporal evolution of the overlying jets and the coincident response of surface fluxes. The present study highlights several factors linking the evolution of low-level jets to surface fluxes: 1) wavelet analysis shows that turbulent fluxes have similar time scales with temporal scale of LLJ evolution; 2) turbulent mixing is enhanced during the transition period of low-level jets; and 3) $\mathrm{CO}_{2}$, water vapor and heat show dissimilarity from momentum during the period. We also found that LLJ activity is related not only to turbulent motions but also to the divergence of mean flow. An examination of scalar profiles and turbulence data reveal that LLJs transport $\mathrm{CO}_{2}$ and water vapor by advection in the stable boundary layer, suggesting that surface fluxes obtained from the micrometeorological method such as nocturnal boundary layer budget technique should carefully interpreted in the presence of LLJs.
\end{abstract}

Key words: $\mathrm{CO}_{2}$ and water vapor exchanges, Surface fluxes, Nocturnal low-level jet, Turbulent mixing, Atmospheric boundary layer

\section{INTRODUCTION}

Micrometeorological techniques such as the eddycovariance (EC) and nocturnal boundary layer (NBL) budget method have been providing invaluable infor- mation about carbon and water exchanges between the vegetation canopy and the overlying atmosphere. Reliable estimation of carbon and water exchanges using micrometeorological techniques is, however, hampered by the inherent limitations of these techniques in the stable boundary layer. For example, though the combined use of the eddy-covariance and the nocturnal boundary-layer budget techniques is complemented in stable atmospheric conditions, these methods might not perform adequately in transient period and have large footprint differences between them (Baldocchi, 2008; Gloor, 2001). In particular, the NBL budget technique assumes negligible amount of horizontal advection like the EC method. In very stable conditions, the annual summation of greenhouse gases and evapotranspiration has required the use of subjective filtering techniques for estimating ecosystem respiration only using turbulent eddy fluxes (Falge et al., 2002; Goulden et al., 1996). Also, a general consensus has yet to be reached on the validity of the scaling in the stable boundary layer such as Monin-Obukhov similarity theory (MOST) and z-less stratification, which is substantial theoretical and experimental difficulties (e.g., Basu et al., 2006; Cheng et al., 2005; Grachev et al., 2005; Pahlow et al., 2001; Finnigan, 1999; Bergström et al., 1995; Dias et al., 1995; Smedman et al., 1995; Nieuwstadt, 1984).

Recent studies have shown that a low-level jet (LLJ) can impact surface fluxes in stably stratified boundary flows (Ohya et al., 2008; Smedman et al., 2004; Banta, 2003; Sun et al., 2002; Beyrich, 1997; Corsmeier et $a l .$, 1997). However, the linkage between LLJs and the corresponding surface flux in stable conditions is still poorly understood and there is disagreement among researchers as to the effects of the LLJ on the turbulence structure (Prabha et al., 2008; Cheng et al., 2005; Smedman et al., 2004). By analyzing stable boundary layer (SBL) data in the Baltic sea, Smedman et al. (2004) argued that SBLs which have a LLJ show tur- 
bulent characteristics of the canonical boundary layer rather than typical values predicted by MOST. They also reported that downward sensible heat fluxes were reduced at the surface by a factor of two because of the shear-sheltering induced by the LLJ. In contrast, Cheng et al. (2005) reported that the downward momentum and heat fluxes increased in the presence of a LLJ. They also showed that MOST appears to be valid during the well-developed stages of a LLJ using non-dimensional wind shear. However, it is not sufficient to test MOST using turbulence statistics (such as the standard deviation of $w\left(\sigma_{w}\right)$ and momentum fluxes) which mainly represent active eddies because of the possibility of interaction between inactive and active eddies even in the stable boundary layer (McNaughton and Brunet, 2002). In addition, LLJs play an important role in the large scale water budget and in thermal mixing by transporting water vapor (Corsmeier et al., 1997; Whiteman et al., 1997; Stensrud, 1996; Izumi and Barad, 1963). But it has not been extensively quantified how much a LLJ transports $\mathrm{CO}_{2}$ and water vapor inside stable boundary layer.

The objective of this study is, during the evolving stage of LLJs, 1) to demonstrate the implications of evolution of low-level jets on nighttime surface flux measurement; and 2) to quantify the amount of $\mathrm{CO}_{2}$ and water vapor transported by LLJs in the SBL. To meet these objectives, we analyzed turbulence statistics and the NBL properties observed by an eddy-covariance system, a tethersonde system and SODAR at a flat site over agricultural land.

\section{MATERIALS AND METHODS}

Profiles of the nocturnal atmosphere were observed using a tethered blimp and SODAR from agricultural land near Côteau-du-Lac, Quêbec, Canada $\left(45^{\circ} 19^{\prime} \mathrm{N}\right.$, $74^{\circ} 10^{\prime} \mathrm{W}$ ) for a two-weeks period in 2003 . In this study, the data collected from 30th to 31st July 2003 were analyzed. The terrain was flat with a slope of about 3 $\mathrm{m}$ over $1.5 \mathrm{~km}$. The blimp launch site was a 20 ha pea field surrounded by corn and vegetable fields, situated about $2.3 \mathrm{~km}$ north-west of the St-Lawrence River. The river is $1.5 \mathrm{~km}$ wide at that location.

A tethered balloon system (AIR, Model TS-5A-SP, Boulder, Co) was instrumented with a sounding instrument package to provide vertical soundings of wind speed, direction, potential temperature, water vapor mixing ratio, and atmospheric pressure. $\mathrm{CO}_{2}$ concentration profiles were also observed using a fast-response $\mathrm{CO}_{2} / \mathrm{H}_{2} \mathrm{O}$ infrared gas analyzer (IRGA) (CIRAS-SC, PP Systems, Hetfordshire, UK) co-located with the sounding instrument package on the blimp. The mete- orological data and $\mathrm{CO}_{2}$ concentration were sampled every 2 and $10 \mathrm{~s}$, respectively. Zero and span calibration for the IRGA were checked prior to the initial flight and following each subsequent one. During each measurement night, multiple blimp ascents of 20-25 min duration were completed approximately every 1.5 hour and the maximum measurement height was approximately $120 \mathrm{~m}$.

The SODAR system (SFAS, Scintec Inc, Tübingen, Germany) was deployed on the site and controlled by Scintec software (APRun, version 1.13) installed on a laptop to which the data was logged. The antenna was surrounded by a $1.3 \mathrm{~m}$ high rigid metal shell with foam on the inside surface to absorb acoustic noise in the immediate vicinity of the sensor and to minimize ground clutter on SODAR data. The system made realtime continuous observations of the three flow components between $10 \mathrm{~m}$ to a maximum level of $250 \mathrm{~m}$ in 5-m vertical increments. Data were averaged over $5 \mathrm{~min}$.

Surface scalars and fluxes were measured at a height of $3 \mathrm{~m}$ using an eddy-covariance system located $60 \mathrm{~m}$ away from the blimp launch site. The eddy-covariance system consisted of a three-dimensional ultrasonic anemometer (Solent R3-HS, Gill Instruments, Lymington, Hampshire, UK) and a closed-path infrared $\mathrm{CO}_{2} /$ $\mathrm{H}_{2} \mathrm{O}$ analyzer (LI6262, LICOR, Lincoln, Nebraska, USA) connected to a data acquisition and control system (Pattey et al., 1996). Measurements were recorded continuously at $20 \mathrm{~Hz}$ and means, standard deviations and fluxes integrated over 5-min following Sun et al. (2002) and Cheng et al. (2005). Nighttime fluxes were screened for $\sigma_{w}<0.1 \mathrm{~ms}^{-1}$ (Pattey et al., 2002). Detailed information is available at (Mathieu et al., 2005).

\section{RESULTS AND DISCUSSION}

\subsection{Evolution of LLJs}

Over the course of the night, several features were observed in relation to the evolutions of low-level jets (Figs. 1 and 2). In Fig. 1a, local wind maxima (red-colored area) were obvious and showed dramatic variation with time. Several transition periods of LLJs during this night were defined in Table 1, according to the stages of LLJ development. The jet developed at a height of around $50 \mathrm{~m}$ in the early evening and persisted through the night (LLJ1). This jet was generated with the wind direction reversal from the land to the river after sunset (P1). Another weak jet existed higher up above LLJ1 prior to 22:00 on the 29th of July (LLJ3) (Fig. 2). Richardson numbers (Ri) derived from tethersonde profiles indicated that the layer around $80 \mathrm{~m}$ was 

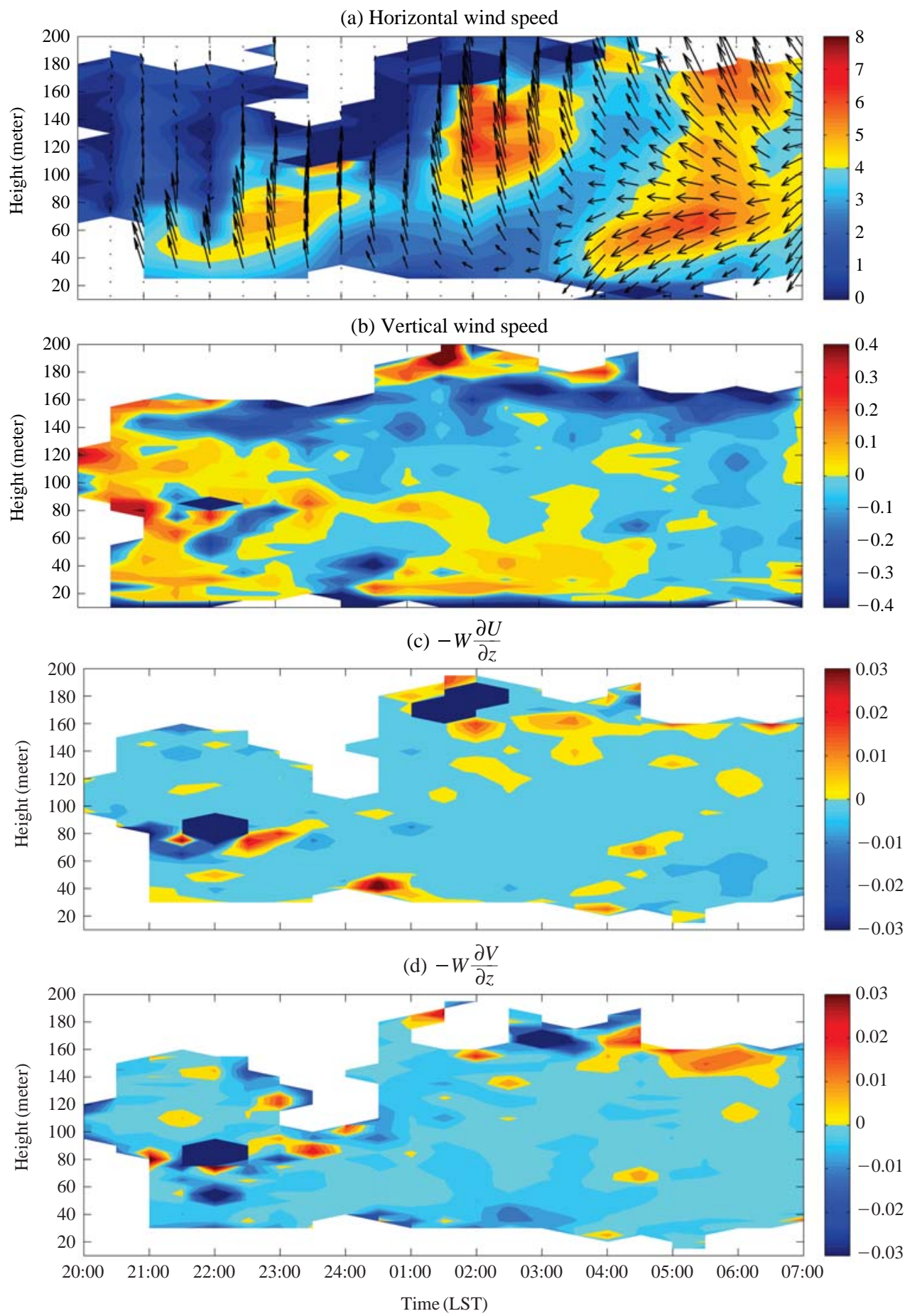

Fig. 1. 30 minutes averaged wind profiles $\left(\mathrm{ms}^{-1}\right)$ and acceleration rates of wind $\left(\mathrm{ms}^{-2}\right)$ due to vertical advection of momentum $\left(-W \frac{\partial U}{\partial z}\right.$ and $\left.-W \frac{\partial V}{\partial z}\right)$ observed by SODAR. Arrow is a horizontal wind vector.

dynamically unstable $(R i \leq 0.25)$ during the time period, P1. At this time, we observed a core of a strong updraft, creating divergence (convergence) of the ver- tical motion below (above) $80 \mathrm{~m}$ (Fig. 1).

LLJ1 was subjected to two disturbance events. During these two disturbances, wind speed decreases were 
Table 1. Summary of the events during the study period.

\begin{tabular}{|c|c|c|}
\hline Event & Time & Characteristics of event \\
\hline P1 & $20: 30-21: 00$ & $\begin{array}{l}\text { The weakness of the LLJ1 around } \\
60 \text { m above the ground. } \\
\text { dynamically unstable }\end{array}$ \\
\hline $\mathrm{P} 2$ & $21: 30-22: 00$ & The deceleration of the LLJ1 \\
\hline P3 & $22: 30-23: 00$ & The acceleration of the LLJ1 \\
\hline P4 & 00:00-01:00 & $\begin{array}{l}\text { The deceleration of the LLJ } 1 \text { and } \\
\text { the strong downdraft below } 60 \mathrm{~m}\end{array}$ \\
\hline P5 & 01:00-02:00 & $\begin{array}{l}\text { The acceleration of the LLJ1 and LLJ3 } \\
\text { with the decrease of wind shear below } \\
60 \mathrm{~m}\end{array}$ \\
\hline P6 & 02:00-03:30 & The development of the LLJ2 \\
\hline
\end{tabular}

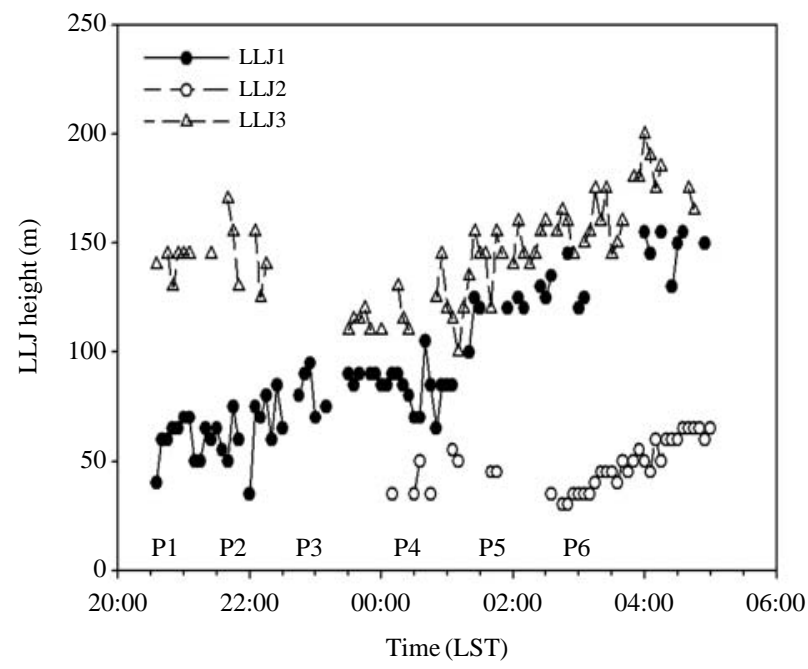

Fig. 2. Evolution of the LLJs. P1-6 refer to the various phases described in Table 1.

accompanied by strong downward motion beneath the nose of the LLJ, which decelerated the meridional wind speeds (Fig. 1a and 1b). The first disruption occurred around 22:00 (P2). The wind shear around the ground at $50 \mathrm{~m}$ suddenly decreased with updraft (downdraft) motions above (below) the LLJ's nose. These downdraft motions persisted for about 30 minutes after LLJ1 re-developed. Ri was less than 0.25 around $50 \mathrm{~m}$ during this period, implying that turbulent mixing played an important role in reducing wind shear during the disruption. Noticeably, turbulent fluxes were enhanced for about 15 minutes when a corresponding strong downdraft existed around $30 \mathrm{~m}$ (Figs. 1 and 5). Particularly, the flux measurements indicated a large $\mathrm{CO}_{2}$ uptake. This disruption lasted for about one hour following which the height of LLJ1 rapidly increased (P3) and then remained stationary for about 1 hour from 23: 30 to 24:00. LLJ3 also re-developed during this peri- od (Fig. 2).

The second disruption occurred after midnight with a sudden decrease of maximum wind speed (P4). Similar to the first disruption, the weakening of the LLJs was accompanied by strong downward motions beneath LLJ1. Additionally, it was observed that the vertical profiles of scalar concentrations significantly changed above $50 \mathrm{~m}$ (around the LLJ1's height) when there was mean flow divergence (Fig. 4). Water vapor and $\mathrm{CO}_{2}$ concentrations significantly increased and temperature decreased up to at least $110 \mathrm{~m}$.

During the second disruption, the wind direction changed from SSE (the river) to NE (the land), and a weak kink in the wind speed profile was generated beneath LLJ1. Following this second event, LLJ1 and LLJ3 rapidly migrated upward and their strength increased with the enhanced turbulence during this period (P5). As the wind direction changes span the entire SBL, another secondary LLJ was generated from this kink (LLJ2). With the appearance of LLJ2, the strength and height of the LLJ1 were reduced and these jets eventually merged together (P6). The convergence of the vertical flows occurred after midnight, possibly suggesting a drainage flow. LLJ2 created a dynamically unstable layer (i.e., $R i \leq 0.25$ ) below $30 \mathrm{~m}$ that was coupled to the ground. The upward motions in the SBL disappeared with the appearance of small $R i$ number just above the ground surface. Finally, all LLJs vanished with the morning development of the convective boundary layers.

Time tendency of wind due to vertical advection was estimated using the conservation equation of momentum (Eqn. (1) and (2)).

$$
\begin{gathered}
\frac{\partial U}{\partial t} \propto-W \frac{\partial U}{\partial z} \\
\frac{\partial V}{\partial t} \propto-W \frac{\partial V}{\partial z}
\end{gathered}
$$

where $t$ is time, $z$ is height, $U, V$, and $W$ are zonal, meridional and vertical wind components, respectively. Noticeably, there were several occurrences of large vertical advection of momentum $\left(W \frac{\partial U}{\partial z}\right.$ and $\left.W \frac{\partial V}{\partial z}\right)$ during the transition periods (P1-P4) around the LLJs' noses and their sign was the same as the time tendency of $\mathrm{U}$ and V. For example, there was the large downdraft motion $\left(\sim 0.4 \mathrm{~ms}^{-1}\right)$ around $60 \mathrm{~m}$ at $22: 00$ and the wind maximum suddenly increased at that time. We speculate that the mean flows controlled this regulation of dynamic instability (i.e., reduction of the wind shear) as did turbulent motions. Several studies showed that burst of turbulent fluxes was related with strong wind shear due to a LLJ in strongly stable conditions (Ohya 

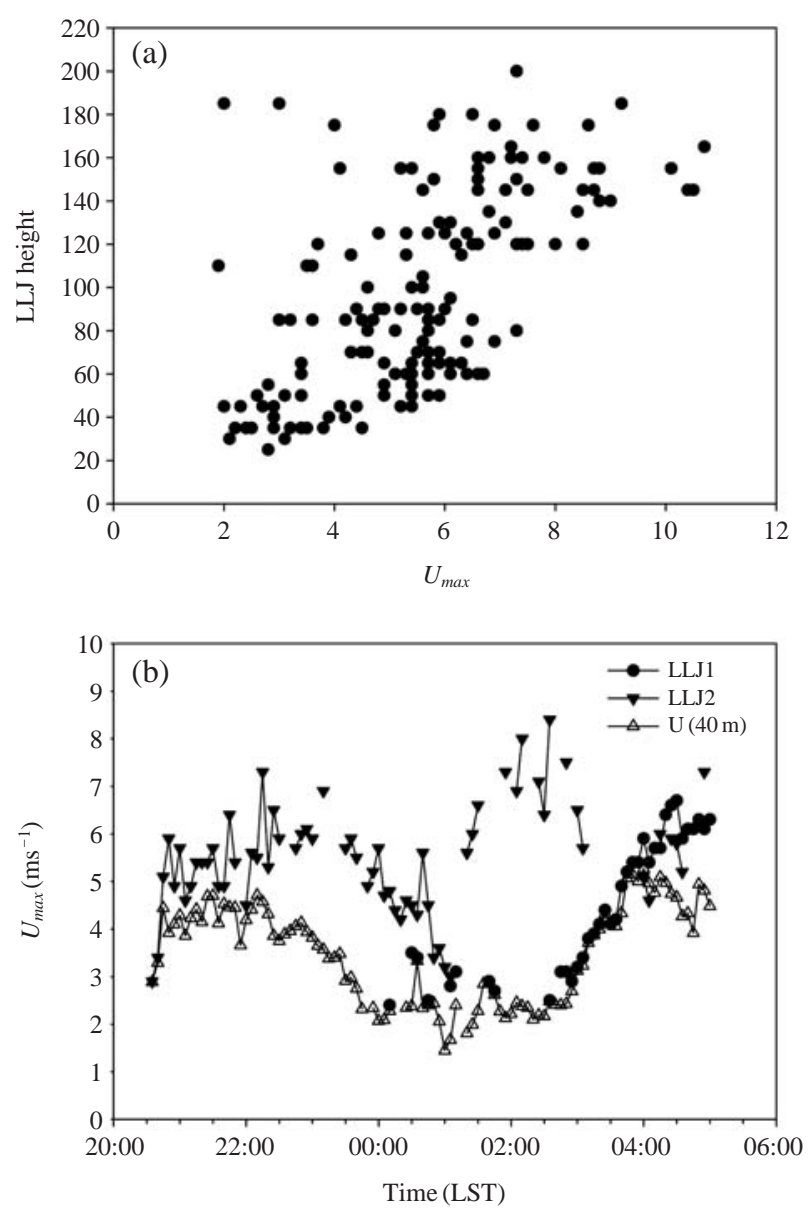

Fig. 3. (a) The height of LLJs as a function of their wind max$\operatorname{imum}\left(U_{\max }\right)$ and (b) time series of $U_{\max }$.

et al., 2008; Sun et al., 2002). Our attention is focused on the role of mean flows to connect turbulent fluxes to a LLJ.

Despite such transient variation of the LLJs, the LLJ maximum wind speed was proportional to the strength of the jet as found in previous studies (Banta et al., 2002) (Fig. 3a). In general, the wind associated with LLJ1 rotated clockwise with time and time changes of $\mathrm{U}$ and $\mathrm{V}$ constituted a pair of the opposite sign before $2: 30$, implying that inertial oscillation and frictional decoupling were plausible mechanism for the generation of LLJ1 during the night (Blackadar, 1957).

Unlike LLJ1, LLJ2, however, did not have property of inertial oscillation. During the period of LLJ2 generation around 3:00, the clockwise rotation was not observed while LLJ3 above LLJ2 still showed clockwise rotation. Also, the wind at the lower SBL clearly manifested the periodic oscillation of about an 8-h period during the night (Fig. 3b). This is far less than the period of inertial oscillation at this latitude. In addition, because synoptic pattern did not change substantially on this night, synoptic scale processes by Uccellini and Johnson (1979) and Chen and Kpaeyeh (1993) also cannot account for the formation of LLJ2. We speculate that generation mechanism of LLJ2 is related with different buoyancy forcing (Mitchell et al., 1995) or drainage flow (Mahrt, 1999). In this regard, LLJ2 was generated with the wind from the land and the generation mechanism of the LLJ2 was due in part to the change of surface wetness. In the next two subsections, we discuss the connection between the LLJs' evolution and the scalar profiles and turbulence structures.

\section{2 Scalar Profiles}

First, we attempted to estimate the amount of enthalpy, water vapor and $\mathrm{CO}_{2}$ transported by LLJs in the period using the property of a LLJ. The Richardson number $(R i)$ was infinite at the wind maximum of an LLJ because of zero wind shear, thereby suppressing the turbulent exchanges. Banta (2003), Mathieu et al. (2005), and Cuxart et al. (2007) reported that the LLJ can act as a cap, blocking the turbulent $\mathrm{CO}_{2}$ transport. Here we estimated the advection below the LLJ but above the EC system by differences between the fluxes at the surface and the time variation of scalar concentrations derived by the NBL budget technique (Eqn.3).

$$
\begin{aligned}
\overline{w^{\prime} \bar{c}^{\prime}} & =\underbrace{\overline{w^{\prime} \bar{c}_{h}}}_{\sim 0}+\int_{0}^{h} \frac{\partial \overline{\mathrm{c}}}{\partial \mathrm{t}} \mathrm{dz} \\
& +\underbrace{\int_{0}^{h} \overline{\mathrm{W}} \frac{\partial \overline{\mathrm{c}}}{\partial \mathrm{z}} \mathrm{dz}+\int_{0}^{h}\left(\bar{u} \frac{\partial \overline{\mathrm{c}}}{\partial \mathrm{x}}+\frac{\partial \overline{\mathrm{u}^{\prime} \mathrm{c}^{\prime}}}{\partial \mathrm{z}}\right) \mathrm{dz}}_{\text {advection }}
\end{aligned}
$$

where $c$ is scalar concentration, $h$ is the NBL height defined by LLJ, and subscript " 0 " implies the measurement height. This rough estimation suggests that there are advective fluxes of more humid $\left(\sim+20 \mathrm{Wm}^{-2}\right)$ and $\mathrm{CO}_{2}$ depleted $\left(-0.3 \mathrm{mg} \mathrm{m}^{-2} \mathrm{~s}^{-1}\right)$ air from 22:15 to $1: 50$ when the wind came from the direction of the river. Also, when the wind changed to easterly again after 2 : 00 , the advective fluxes changed sign $\left(-20 \mathrm{Wm}^{-2}\right.$ for latent heat flux and $+0.2 \mathrm{mg} \mathrm{m}^{-2} \mathrm{~s}^{-1}$ for $\mathrm{CO}_{2}$ fluxes).

Compared to the relatively large $\mathrm{CO}_{2}$ fluxes observed at the tower $\left(\sim 1 \mathrm{mg} \mathrm{m}^{-2} \mathrm{~s}^{-1}\right)$, the NBL budget technique results indicated that $\mathrm{CO}_{2}$ fluxes of $<0.1 \mathrm{mg}$ $\mathrm{m}^{-2} \mathrm{~s}^{-1}$ were enough to account for the variation in the $\mathrm{CO}_{2}$ concentration profile during the 2.5 hour period from 19:30. However, sensible heat fluxes from the tower did not show significant differences from the NBL technique, suggesting that turbulent fluxes were sufficient to result in the observed temperature decrease during this period. $\mathrm{CO}_{2}$ depleted and humidity enriched air moved from the river during this period, but likely the temperature differences between the river and land 

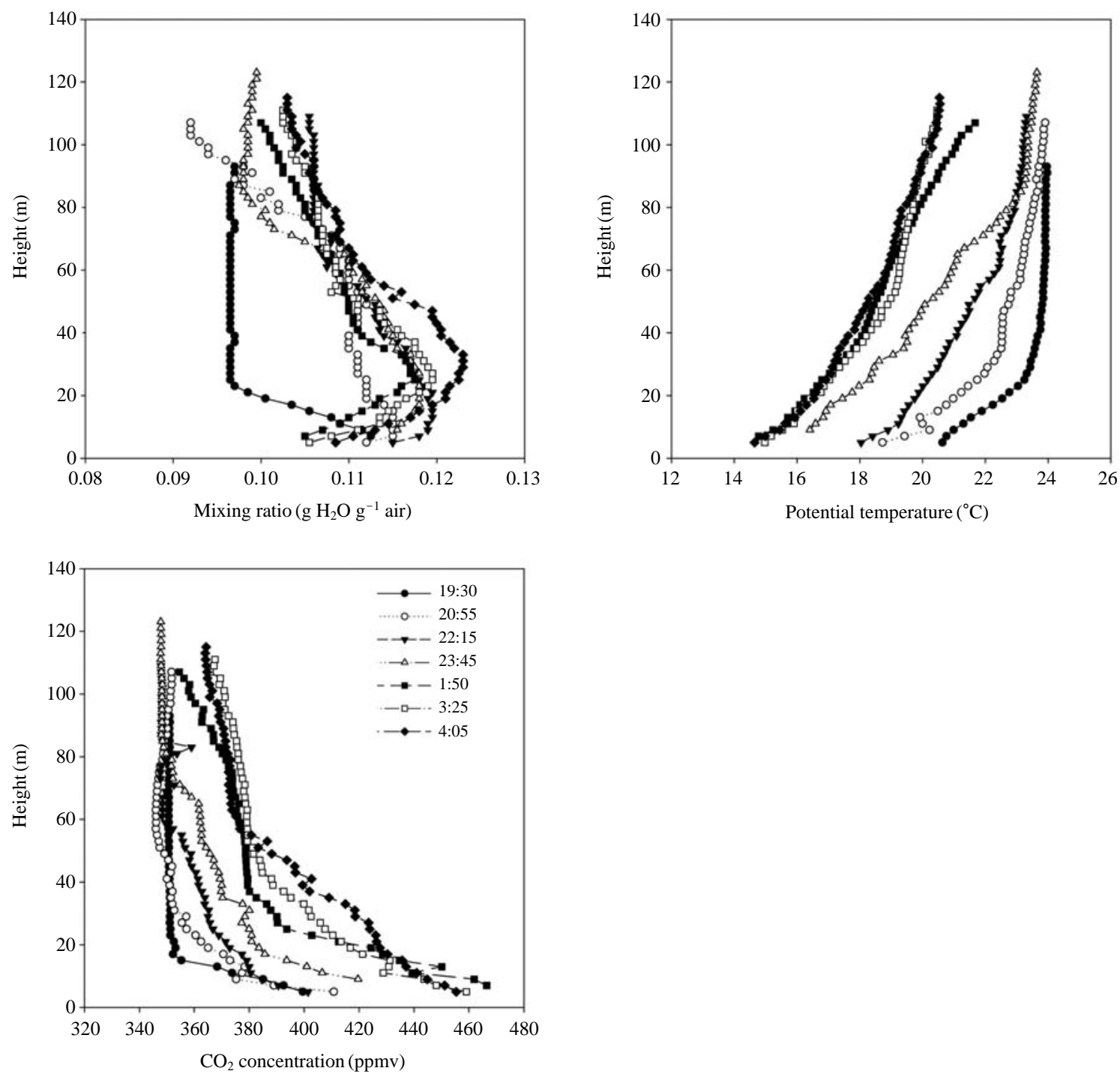

Fig. 4. Tethersonde observations of water vapor mixing ratio, potential temperature and $\mathrm{CO}_{2}$ concentration.

were not sufficiently large to cause changes in the observed temperature profile.

The opposite situation occurred above the LLJ around 23:30. Tethersonde observations showed that both $\mathrm{CO}_{2}$ concentration and water vapor decreased above LLJ1 $(>70 \mathrm{~m})$ at $23: 45$ but that temperature slightly increased. In particular, water vapor profile clearly showed a decreasing pattern. In this layer, potential temperatures were observed to increase without a significant change in the vertical gradient of potential temperature. Compared to water vapor and $\mathrm{CO}_{2}$ concentrations, temperature did not show a dramatic variation, probably because there was not as significant temperature difference between the site and the river. As mentioned previously, a strong updraft was observed at the center of
LLJ1, creating convergence of the vertical flow. It is probable that divergence in horizontal flow existed in this layer and that $q$ and $c$ diminished in this layer.

Scalar profiles consistently revealed temporal variation with the evolution of LLJs and surface fluxes. Fig. 4 shows potential temperature $(T)$, water vapor mixing ratio $(q)$ and $\mathrm{CO}_{2}$ concentration $(c)$ profiles from the tethersonde. Before the sunset, sensible heat fluxes at the surface were nearly zero and all scalar profiles exhibited the mixed layer structure before 20:00 above $20 \mathrm{~m}$ from the ground surface. During the generation of the LLJ1 (P1), water vapor significantly increased. Surface fluxes showed the abrupt peaks for about 15 minutes and the vertical gradient of the scalars was reduced below $60 \mathrm{~m}$ (Fig. 5). This indicates that tur- 
bulent activity increased during the generation of the LLJ1. However, it is noteworthy that even such sudden increases in latent heat fluxes for about 20 minutes could not explain the increment of $q$ in the whole SBL, suggesting that advective fluxes existed.

The SODAR observation gives some clues to the advective fluxes around 20:30. First, there was a strong updraft at $70 \mathrm{~m}$ (Fig. 1). This indicates the divergence of vertical wind, thereby the convergence of horizontal wind (from the incompressible flow assumption). We note that this updraft occurred with the development of the LLJ when southeasterly flow was dominant. At that time, the wind direction changed from the agricultural land (easterly) to the river (southeasterly). It is probable that the air mass became enriched in humidity after the change of the wind direction to the river and therefore water vapor was transported by the convergence of horizontal wind to the site. We speculate that the LLJ below $100 \mathrm{~m}$ transported the moisture accumulated in the air around the river, that is only 2 $\mathrm{km}$ away from the tower.

The scalar concentration profiles indicate different behavior from midnight to 2:00. During this period, there was a large increase in $\mathrm{CO}_{2}$ concentration. Temperature and water vapor demonstrated the reverse pattern. With a decrease in temperature and water vapor in the upper SBL, the lapse rate of temperature became smaller and water vapor decreased in the lower SBL, thereby decreasing the vertical temperature gradients. In general, the scalar profiles showed a reduction in vertical gradients through mixing.

During P4 and P5, friction velocity was enhanced, indicating that flows were relatively more turbulent compared to other periods (Fig. 5). The vertical advection was negative because of the downdraft motion and the positive vertical gradient of $\mathrm{CO}_{2}$ concentration in this layer. Therefore, vertical advection cannot explain the observed pattern of the scalar profiles at this time. We note that the LLJs became weak and the relatively strong convergence of horizontal motions were maintained following the strong downward motion observed during P4 in the lower SBL. At that time, easterly flow becomes predominant below $50 \mathrm{~m}$. The weakening of the LLJs implies a decline of the transport from the river. In particular, the offshore flow with LLJ2 in the lower SBL transported the accumulated $\mathrm{CO}_{2}$ over the land with a corresponding depletion of water vapor. This scenario agrees well with the observed scalar profiles after midnight.

We also note a kink in the $q$ profile around $30 \mathrm{~m}$. This was observed first at 23:45 and maintained through the end of the night. During this period, $\mathrm{CO}_{2}$ concentration beneath the height of this kink shows a decrease of $10 \mathrm{ppm}$ despite the ecosystem respiration. During this period, wind direction changed away from the river, probably decreasing of moisture transport below LLJ2. This kink in the $q$ profile can be partially attributed to a drainage flow, turbulent mixing and/or the vertical advection. At that time, there was a core of large strong upward motion around $30 \mathrm{~m}$ and wind blows from the land, implying the possibility of sweep motions by a drainage flow. Negative vertical advection partially accounts for this kink. Unlike other periods, LLJ 2 created a dynamically unstable layer below $30 \mathrm{~m}$ which coupled the turbulent motions to the ground. Vertical gradients of the scalar concentrations decreased through the eddies attached to the ground.

During this period, the observed large downward sensible heat fluxes also were maintained. In general, the temperature profile did not show substantial temporal changes after 2:00 despite the similar net radiative flux density and the relatively large downward sensible heat fluxes. The transport through LLJ2 and the suspected presence of a drainage flow indirectly suggests the existence of warm advection.

Izumi and Barad (1963) and Whiteman et al. (1997) showed that the SBL temperature profile was influenced by mixing associated with the LLJ. In addition to turbulent mixing, our data set shows that not only water vapor, but also $\mathrm{CO}_{2}$ and temperature were significantly transported by the LLJ inside the stable boundary layer. Temperature, water vapor and $\mathrm{CO}_{2}$ concentration profiles indirectly show that there was horizontal advection transport by the LLJ.

\section{3 Turbulence Statistics}

Fig. 5 presents the observed surface turbulent fluxes and their wavelet power spectra. Friction velocities $\left(u_{*}\right)$ were enhanced at each transition period of the LLJs (P1-P6), implying that the stable surface layer became highly turbulent. It has been thought that the LLJ could be a source of turbulence in the SBL due to the strong wind shear and that increasing turbulent activity reduced the LLJ again (Grachev et al., 2005; Finnigan, 1999). Our data also shows that the stable boundary layer becomes increasingly turbulent when an LLJ accelerates or decelerates.

In general, the wavelet power spectrum of friction velocity concentrates on two scales of 30 minutes and 9 hour. During the study period, the evolution of the LLJs occurred within 1 hour and the friction velocity variances had a local peak at the scale of 30 minutes and 1 hour. This suggests that a 30-minute averaging time is not sufficient to capture the response of surface fluxes to the evolution of low-level jets. We also note the peaks at about 9 hours in all turbulent fluxes. As pointed out, the LLJs evolved on the scale of 9 hours and their combined variation was clearly observed in 

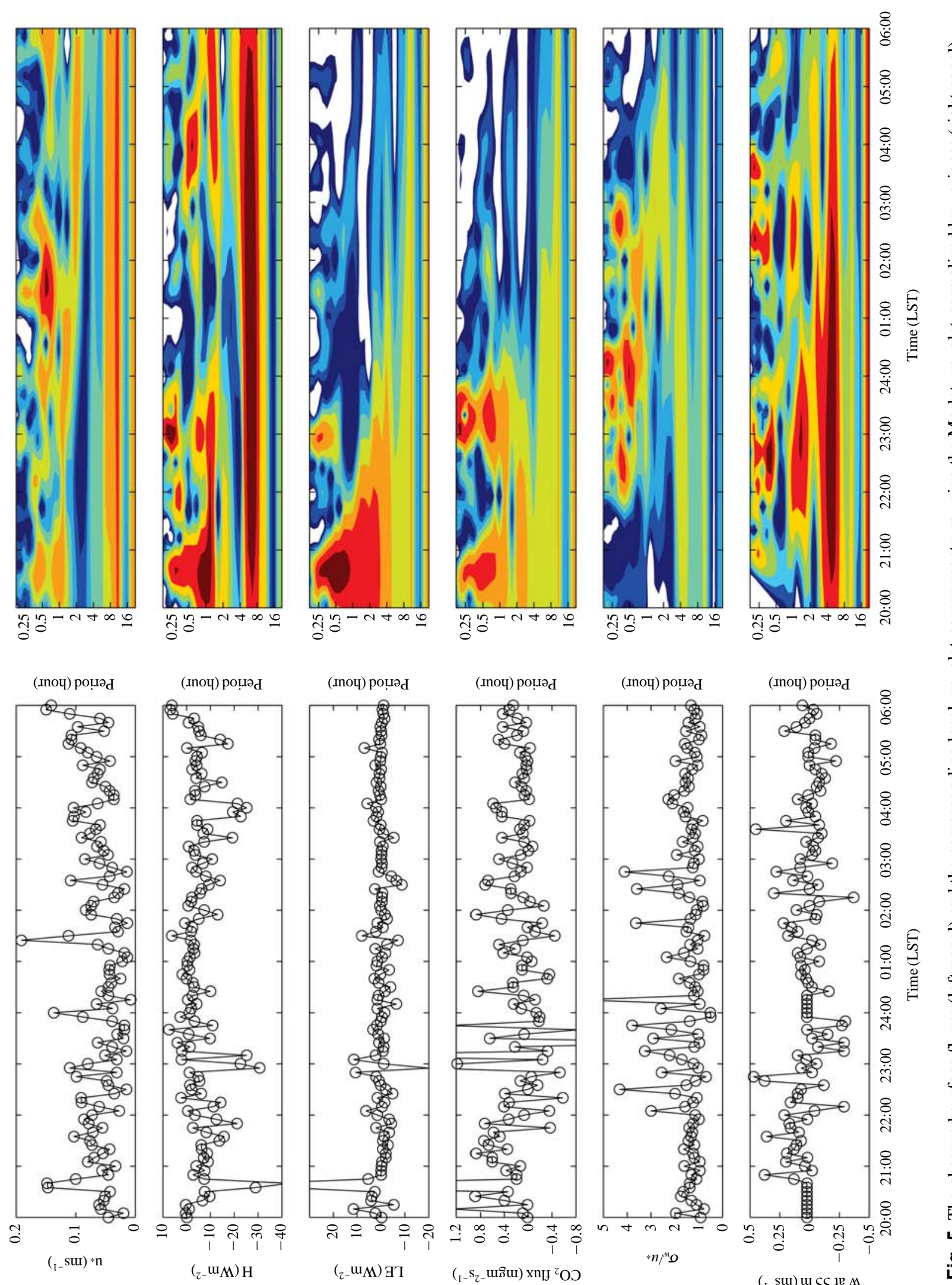

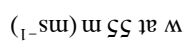

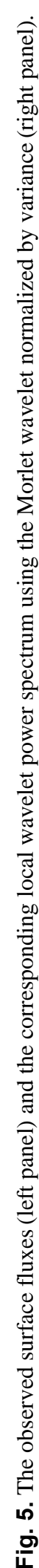



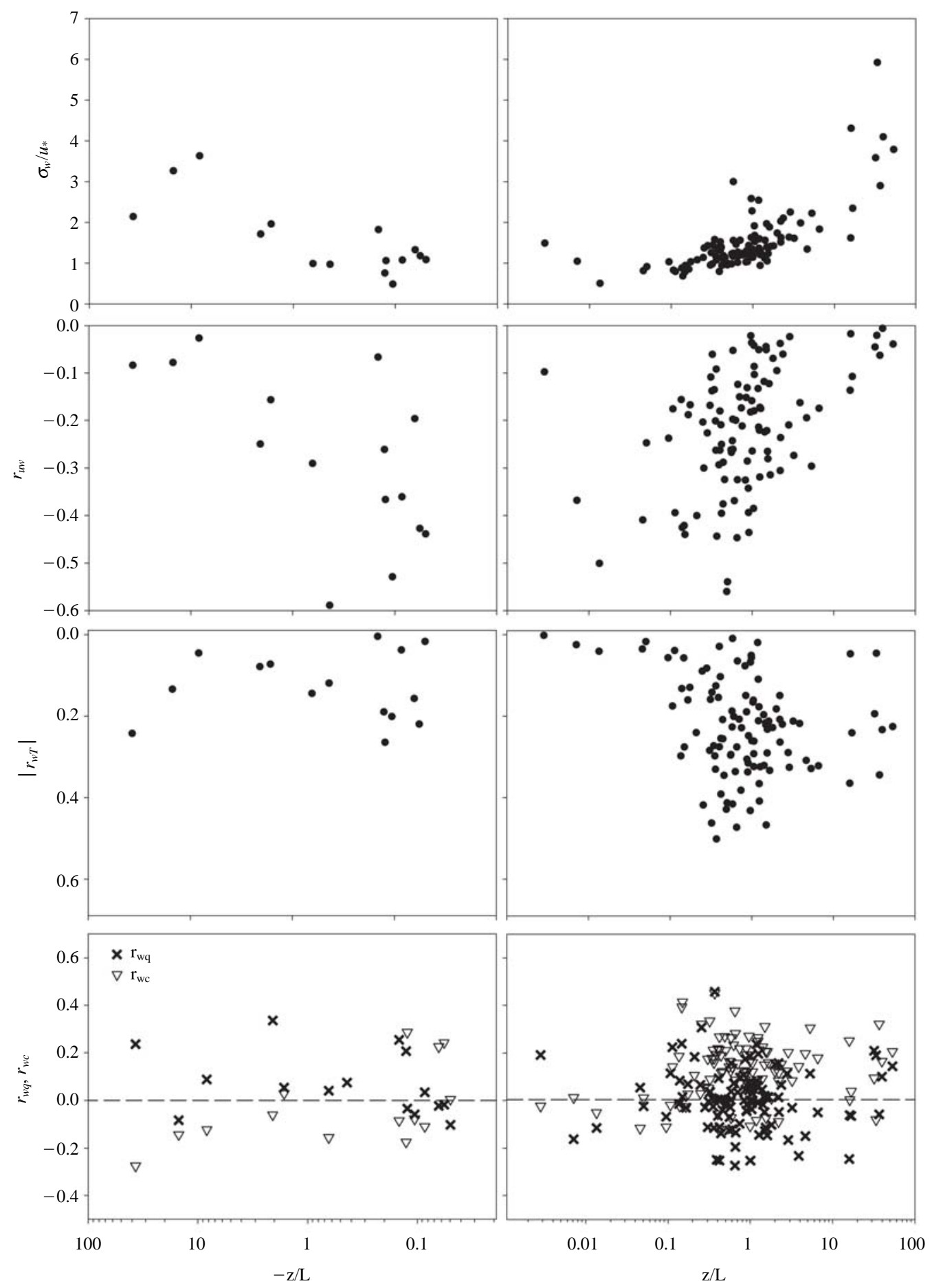

Fig. 6. $\sigma_{w} / u_{*}$ and correlation coefficients of $w$ with $u\left(r_{u w}\right)$, temperature $\left(r_{w T}\right)$, water vapor $\left(r_{w q}\right)$, and $\mathrm{CO}_{2}\left(r_{w c}\right) . z$ is the measurement height and $L$ is Obukhov length.

the wind speed around $60 \mathrm{~m}$. It suggests the possibility that the surface fluxes were closely related to the slowly moving component of LLJ intensity. Particularly, there was a spectral gap between about 8 and 24 hours, indicating that the LLJ evolution constrained the turbulent eddies between the diurnal cycle and the averaging time for flux calculations (from $\sim 30$ minutes to 1 hour). 
The wavelet power spectrum of friction velocity has several peaks at different scales and times. All scalar fluxes had local peaks of $\sim 15$ minutes and $\sim 1$ hour periods at around 20:30 and 23:20. When there was strong downward motion $\left(<0.2 \mathrm{~ms}^{-1}\right)$ below the LLJs $(21: 30$ 22:30 and 24:00-01:00), the scalar fluxes became weak despite strong turbulent activity. Also, we note that the spectral peaks of each scalar fluxes occurred with different periods and times, indicating the dissimilarity between temperature, water vapor and $\mathrm{CO}_{2}$. The integral turbulence characteristics of each scalar also corroborate this statement (Fig. 6) and we speculate that the transport by LLJs generated heterogeneity in the scalar fields.

$\sigma_{w} / u_{*}$ showed a good relationship with atmospheric stability (Fig. 6). In contrast, its scalar counterparts were not well behaved functions of atmospheric stability. Three explanations are possible. First, it may simply imply that MOST is not valid under the evolving LLJ because of the inherent nonstationarity of LLJs and intermittency of turbulence during that time. Another possibility is the different source/sink distributions among scalars due to surface heterogeneity and/ or LLJ's transport (Williams et al., 2007; Andreas et al., 1998). Also it is possible that the inactive and active eddies interact even in the SBL. Recently, McNaughton and Brunet (2002) and McNaughton (2006) argued that inactive eddies interact with active eddies in unstable boundary layers. By showing the deviation of heat fluxes from MOST, McNaughton and Brunet (2002) showed experimental evidence of such an interaction in unstable boundary layers. Because momentum fluxes consist of active turbulence, we should also assess the scalar behavior to check such interactions. Our data shows that the correlation coefficient for $u$ (longitudinal wind) and $w$ (vertical wind), $r_{u w}$ had typical values $(-0.25-0.45)$ at near neutral conditions and turbulent efficiencies between $\mathrm{w}$ and scalars were not so small in strongly stable conditions despite nearly zero $r_{u w}$, albeit scatter in the data (Fig. 6). That is, turbulent scalar fluxes were enhanced even in relatively smaller momentum exchanges.

Basu et al. (2006) summarized that $\sigma_{w} / u_{*}$ was about 1.4 in z-less stratification. $\sigma_{w} / u_{*}$ did not show z-less stratification in our case, regardless of averaging time. In strongly stable conditions $(z / L>1)$, the influence of height, $z$ appeared again and the z-less regime vanished. Similar properties were also reported by Smedman (1988) when there was an LLJ. Recently, Smedman et al. (2004) reported that the turbulent activity diminished when an LLJ existed despite the strong wind shear by an LLJ and they argued that was the evidence of the shear sheltering. They reported the significant reduction of sensible heat fluxes by an LLJ, but the increased transfer efficiency by $r_{u w}$ as the evidence. In our case study, $r_{u w}$ is, however, nearly -0.4 in the nearneutral conditions and there was no direct evidence of the fully developed LLJ status reported by Smedman et al. (2004).

\section{SUMMARY AND CONCLUSIONS}

We analyzed the wind and scalar profiles and turbulence statistics in the stable boundary layer observed by a flux tower, tethersonde and SODAR. During the observation period, several low-level jets were observed to evolve with time. LLJs show the temporal variation of wind maxima and heights of jets and LLJs are generated by different mechanisms. Through the combination of these data sets, we observed the interplays between LLJs and the turbulence structure in the SBL that will shed light on the estimation of nighttime mass and energy exchanges: (1) the divergence of air due to the acceleration of low-level jet plays an important role in transporting water and $\mathrm{CO}_{2}$. Previous studies reported that an LLJ plays an important role in the large scale water vapor transport from remote areas (Whiteman et al., 1997; Stensrud, 1996). Our data shows that the transport by an LLJ is also important in the budgets of $\mathrm{CO}_{2}$, water vapor, temperature and momentum at landscape scale; (2) the dynamic instability seen through small Richardson numbers is stabilized through not only turbulent motions, but also the mean flows; (3) despite the evolving property of an LLJ, many portions of turbulent statistics of wind components can be expressed as a functions of the atmospheric stability just above the ground surface possibly due to the dominant role of surface friction but we observed dissimilarity between different scalars possibly due to the heterogeneity created through LLJ transport or the interaction between active and inactive eddies; (4) turbulent activity is enhanced during the transition period of the evolving LLJ and advective fluxes below an LLJ are substantial, indicating that we should carefully apply the $u_{*}$ correction for nighttime data filtering because strong turbulent mixing cannot guarantee the negligence of the advection; and (5) we show the possibility of the impact of surface water conditions on the LLJ generation and turbulence structure. In particular, we should increase the averaging time in the flux calculation to capture the LLJ's contribution even in the stable conditions.

\section{ACKNOWLEDGEMENT}

This work was funded by the Korea Meteorological 
Administration Research and Development Program under Grant CATER 2012-3034 and 2012-3055 and by Yonsei University Research Fund of 2012-1-0100. The authors wish to thank Mr. G. Vincent for access to his land and two reviewers for their constructive comments on this paper.

\section{REFERENCES}

Andreas, E.L., Hill, R.J., Gosz, J.R., Moore, D., Otto, W. D., Sarma, A.D. (1998) Statistics of surface-layer turbulence over terrain with metre-scale heterogeneity. Boundary-Layer Meteorology 86, 379-408.

Baldocchi, D.D. (2008) Breathing of the terrestrial biosphere: Lessons learned from a global network of carbon dioxide flux measurement systems. Australian Journal of Botany 56, 1-26.

Banta, R.M. (2003) Relationship between low-level jet properties and turbulence kinetic energy in the nocturnal stable boundary layer. Journal of Atmospheric Sciences 60, 2549-2555.

Banta, R.M., Newsom, R.K., Lundquist, J.K., Pichugina, Y.L., Coulter, R.L., Mahrt, L. (2002) Nocturnal lowlevel jet characteristics over Kansas during cases-99. Boundary-Layer Meteorology 105, 221-252.

Basu, S., Porte-Agel, F., Foufoula-Georgiou, E., Vinuesa, J.F., Pahlow, M. (2006) Revisiting the local scaling hypothesis in stably stratified atmospheric boundarylayer turbulence: An integration of field and laboratory measurements with large-eddy simulations. BoundaryLayer Meteorology 119, 473-500.

Bergstöm, H., Smedman, A.S. (1995) Stably stratified flow in a marine atmospheric surface-layer. Boundary-Layer Meteorology 72, 239-265.

Beyrich, F. (1997) Mixing height estimation from SODAR data - a critical discussion. Atmospheric Environment 31, 3941-3953.

Blackadar, A.K. (1957) Boundary layer wind maxima and their significant for the growth of nocturnal inversions. Bulletin of American Meteorological Society 38, 283290.

Chen, T.C., Kpaeyeh, J.A. (1993) The synoptic-scale environment associated with the low-level jet of the greatplains. Monthly Weather Review 121, 416-420.

Cheng, Y., Parlange, M., Brutsaert, W. (2005) Pathology of Monin-Obukhov similarity in the stable boundary layer. Journal of Geophysical Research 110, D06101, doi:10.1029/2004JD004923.

Corsmeier, U., Kalthoff, N., Kolle, O., Kotzian, M., Fiedler, F. (1997) Ozone concentration jump in the stable nocturnal boundary layer during a LLJ-event. Atmospheric Environment 31, 1977-1989.

Cuxart, J., Jimenez, M.A. (2007) Mixing processes in a nocturnal low-level jet: An LES study. Journal of Atmospheric Sciences 64, 1666-1679.

Dias, N.L., Brutsaert, W., Wesely, M.L. (1995) Z-less strat- ification under stable conditions. Boundary-Layer Meteorology 75, 175-187.

Falge, E., Baldocchi, D., Tenhunen, J., Aubinet, M., Bakwin, P., Berbigier, P., Bernhofer, C., Burba, G., Clement, R., Davis, K.J., Elbers, J.A., Goldstein, A.H., Grelle, A., Granier, A., Guomundsson, J., Hollinger, D., Kowa1ski, A.S., Katul, G., Law, B.E., Malhi, Y., Meyers, T., Monson, R.K., Munger, J.W., Oechel, W., Paw, K.T., Pilegaard, K., Rannik, U., Rebmann, C., Suyker, A., Valentini, R., Wilson, K., Wofsy, S. (2002) Seasonality of ecosystem respiration and gross primary production as derived from FluxNet measurements. Agricultural and Forest Meteorology 113, 53-74.

Finnigan, J.J. (1999) A note on wave-turbulence interaction and the possibility of scaling the very stable boundary layer. Boundary-Layer Meteorology 90, 529-539.

Gloor, M. (2001) What is the concentration footprint of a tall tower? Journal of Geophysical Research 106, 17 831-17 840.

Goulden, M., Munger, J.W., Fan, S.M., Daube, B.C., Wofsy, S.C. (1996) Measurements of carbon sequestration by long-term eddy covariance: Methods and a critical evaluation of accuracy. Global Change Biology 2, 169-182.

Grachev, A.A., Fairall, C.W., Persson, P.O.G., Andreas, E.L., Guest, P.S. (2005) Stable boundary-layer scaling regimes: The SHEBA data. Boundary-Layer Meteorology 116, 201-235.

Izumi, Y., Barad, M.L. (1963) Wind and temperature variations during the development of a low-level jet. Journal of Applied Meteorology 2, 668-673.

Mahrt, L. (1999) Stratified atmospheric boundary layers. Boundary-Layer Meteorology 90, 375-396.

Mathieu, N., Strachan, I.B., Leclerc, M.Y., Karipot, A., Pattey, E. (2005) Role of low-level jets and boundarylayer properties on the NBL budget technique. Agricultural and Forest Meteorology 135, 35-43.

McNaughton, K.G. (2006) On the kinetic energy budget of the unstable atmospheric surface layer. BoundaryLayer Meteorology, 118, 83-107.

McNaughton, K.G. Brunet, Y. (2002) Townsend's hypothesis, coherent structures and Monin-Obukhov similarity. Boundary-Layer Meteorology 102, 161-175.

Mitchell, M.J., Arritt, R.W., Labas, K. (1995) A climatology of the warm-season great-plains low-level jet using wind profiler observations. Weather and Forecasting 10, 576-591.

Nieuwstadt, F.T.M. (1984) Some aspects of the turbulent stable boundary layer. Boundary-Layer Meteorology 30, 31-55.

Ohya, Y., Nakamura, R., Uchida, T. (2008) Intermittent bursting of turbulence in a stable boundary layer with low-level jet. Boundary-Layer Meteorology 126, 349363.

Pahlow, M., Parlange, M.B., Porte-Agel, F. (2001) On Monin-Obukhov similarity in the stable atmospheric boundary layer. Boundary-Layer Meteorology 99, 225248. 
Pattey, E., Strachan, I.B., Desjardins, R.L., Massheder, J. (2002) Measuring nighttime $\mathrm{CO}_{2}$ flux over terrestrial ecosystems using eddy covariance and nocturnal boundary layer methods. Agricultural and Forest Meteorology 113, 145-158.

Prabha, T.V., Leclerc, M.Y., Karipot, A. (2007) Low-frequency effects on eddy covariance fluxes under the influence of a low-level jet. Journal of Applied Meteorology and Climatology 46, 338-352.

Smedman, A.S. (1988) Observations of a multi-level turbulence structure in a very stable atmospheric boundarylayer. Boundary-Layer Meteorology 44, 231-253.

Smedman, A.S., Bergström, H., Högstrom, U. (1995) Spectra, variances and length scales in a marine stable boundary layer dominated by a low level jet. BoundaryLayer Meteorology 76, 211-232.

Smedman, A.S., Högstrom, U., Hunt, J.C.R. (2004) Effects of shear sheltering in a stable atmospheric boundary layer with strong shear. Quarterly Journal of the Royal Meteorological Society 130, 31-50.

Stensrud, D.J. (1996) Importance of low-level jets to climate: A review. Journal of Climate 9, 1698-1711.
Sun, J.L., Burns, S.P., Lenschow, D.H., Banta, R., Newsom, R., Coulter, R., Frasier, S., Ince, T., Nappo, C., Cuxart, J., Blumen, W., Lee, X., Hu, X.Z. (2002) Intermittent turbulence associated with a density current passage in the stable boundary layer. Boundary-Layer Meteorology 105, 199-219.

Uccellini, L., Johnson, D. (1979) Coupling of upper and lower tropospheric jet streaks and implications for the development of severe convective storms. Monthly Weather Review 107, 682-703.

Whiteman, C.D., Bian, X.D., Zhong, S.Y. (1997) Lowlevel jet climatology from enhanced rawinsonde observations at a site in the southern great plains. Journal of Applied Meteorology 36, 1363-1376.

Williams, C., Scanlon, T., Albertson, J. (2007) Influence of surface heterogeneity on scalar dissimilarity in the roughness sublayer. Boundary-Layer Meteorology 122, 149-165.

(Received 23 August 2011, revised 9 August 2012, accepted 9 August 2012) 